\title{
The programme of Aristotelian analytics ${ }^{* 1}$
}

\author{
Michel Crubellier**
}

\begin{abstract}
In this paper, I submit an overall interpretation of Aristotle's Analytics (Posterior as well as Prior) which I could express, to put it in a nutshell, by saying that the Analytics are analytic. That is, they do not lay out progressive or constructive processes, in which, given certain fundamental premises, terms or rules, one would go ahead and draw conclusions or even build a systematic body of knowledge on the basis of these principles. Rather they describe a backward movement, starting from a proposed or provisional conclusion and asking which premises could (or could best) be used in order to deduce, support, prove or explain it.
\end{abstract}

Keywords: Aristotle, Analytics, Syllogism, Science.

\section{Resumen}

\section{El programa de análisis aristotélico}

En este documento, presento una interpretación general de los Primeros y Segundos Analíticos de Aristóteles que podría expresar, para decirlo en pocas palabras, el punto de vista de que los Analíticos de

\footnotetext{
* Recibido: noviembre 2017. Aceptado: diciembre 2017.

** Université de Lille. Lille, France. Email: michel.crubellier@orange.fr

${ }^{1}$ I have expounded the ideas that I develop here before various audiences, in Paris and Nanterre in 2001, and in Créteil in 2005. I want to thank my hosts, Pierre Pellegrin, Francis Wolff and Souad Ayada, for giving me these opportunities to test my views and (I hope) to improve them on some important points. During the same period, I had opportunities to present them to my students and to some colleagues in Lille, and I benefited greatly from long and exciting discussions with Shahid Rahman and his logician friends and students. I also want to thank the colleagues who read this paper and commented on it, and especially Pr. Robin Smith; I felt much encouraged by their positive comments, which made my own ideas much clearer even to myself. Of course, the remaining faults are mine.
}

An outline of the same views, much shorter and less systematic, was published in Crubellier \& Pellegrin 2002 (chapter 2). 
Aristóteles son analíticos. Es decir, no establecen procesos progresivos o constructivos, en los que, dadas ciertas premisas, términos o reglas fundamentales, uno podría avanzar y sacar conclusiones o incluso construir un cuerpo sistemático de conocimiento sobre la base de estos principios. Más bien, describen un retroceso, a partir de una conclusión propuesta o provisional y preguntando qué premisas podrían (o podrían mejor) ser utilizadas para deducir, apoyar, probar o explicar.

Palabras clave: Aristóteles, Analíticos, silogismo, ciencia.

\section{On the title Analytics}

These views arose from certain perplexities I have long had about the title Analytics (which is most certainly genuine, to judge from the numbers of mentions in the Corpus and from the fact that many of them could hardly have been later additions made by an ancient editor). This title raises immediately two problems:

(1) it is common to two quite different works, one of which is supposed to be a treatise of formal logic (the so-called "syllogistic"), while the other one is about the epistemology and methodology of exact sciences. There are some very clear indications that Aristotle, even if he wrote them at distinct (and maybe distant) times of his life, did regard them as two parts of one and the same project. See for instance the beginning of An. Pr. I 4: "Having made these determinations, let us now say through what premises, when and how every deduction comes about. We will need to discuss demonstration later. Deduction should be discussed before demonstration, because deduction is more universal: a demonstration is a kind of deduction, but not every deduction is a demonstration". ${ }^{2}$ This passage is ech-

\footnotetext{
${ }^{2}$ Pr. An. I 4, 25b 26-31. - I quote the Prior Analytics in Smith's translation (Smith 1989), and other Aristotelian texts in the "Revised Oxford Translation", into which I made such changes as were required (1) to match the interpretations that I want to defend and (2) to obtain sufficient terminological homogeneity between different treatises. To avoid making my footnotes too cumbersome, I did not attempt, except on very few occasions, to indicate and justify these changes. I hope that readers who would like to compare my citations with Smith and the ROT will easily understand what I have changed and why. For the same reason, I tried to leave aside, as far as possible, the many linguistic and philological questions raised by these passages. I only wish to mention here that although I did not keep Barnes' rendering of episteme through "understanding", I do think that there are good reasons to support it (Burnyeat 1981); but I thought that the traditional translation through "science" would be more evident to those readers who are not sedulous Aristotelians.
} 
oed by the first lines of the last chapter of the Post. An.: "Now as for deduction and demonstration, it is evident both what each is and how it made up". ${ }^{3}$

(2) The word Analutika itself might appear surprising. If "deduction" and "demonstration" were to be conceived of - as it is generally admitted - as constructive processes, starting with the assumption of certain propositions and then proceeding on to the conclusions that the premises logically entail, how strange it would be to call these treatises Analytics! The verb analuein, on the contrary, indicates the splitting-up of a whole into its component parts. One use of the word, probably the most frequent in the Aristotelian corpus, means the way in which all natural objects may be decomposed into the four simple bodies, earth, water, air and fire. Aristotle also knows the "analytic" method used in geometry for the resolution of some problems. ${ }^{4}$ The third important use is the one I want to elucidate in this paper.

In the following pages, I will use the word analytics (without a capital) to indicate the peculiar ability (which is not a science) that one may acquire through reading and working up the Analytics (the treatises), just as Brunschwig once proposed to call topics the peculiar ability which you may acquire through reading and practice of Aristotle's Topics. The person who practises the analytical ability I will sometimes call "the analyst".

\section{The plan of the Prior Analytics}

What is the project of Aristotle's analytics? The opening pages of the first treatise give us very few indications about that question. After having given in the first chapter, without any comment, a small number of inaugural definitions, Aristotle immediately enters into his subject matter. But later in Book I, there are two important passages that, while emphasizing a transition, do disclose a larger plan:

- Transition between chapters 26 and 27 of Book I:

"[a] From what has been said, then, it is clear how every deduction comes about, both through how many terms and premises and what rela-

\footnotetext{
${ }^{3}$ Post. An. II 19, 99b 15-16. - We may be tempted to infer from this that the last chapter of Post. An. is entirely distinct from the rest of the two treatises; or even that, indeed, the whole is divided into two distinct parts (although these would be quite unequal in length), the first one dealing with deduction and the second one with induction. But on this see section 6 below.
}

${ }^{4}$ See for instance Nicomachean Ethics III, 1112b 21-22. 
tionship they are in to one another, and furthermore what sort of problem is proved in each figure, and what sort in more, and what in fewer figures. Now it is time to explain [b] how we may ourselves always be supplied with deductions about what is set up and the route by which we may obtain the principles concerning any particular subject. For surely one ought not only study the origin of deductions, but also have the power to produce them". ${ }^{5}$

\section{- Transition between chapters 31 and 32 of Book II:}

"It is evident from the things which have been said, then, [a] what all demonstrations come from, and how, and [b] what things one should look to in the case of each problem. But after these things, we must [c] explain how we can lead deductions back into the figures stated previously; for this part of the inquiry still remains. For if we should [a] study the origin of deductions, and [b] also should have the power of finding them, and if, moreover [c] we could resolve (analuoimen) the existing deductions into the figures previously stated, then our initial project would have reached its goal. It will also result at the same time that what we have said previously will be rendered more secure, and it will be clearer that this is how things are, by what we are now about to say; for all that is true must in all ways be in agreement with itself". ${ }^{6}$

These passages suggest that the Prior Analytics divide into three main parts, corresponding to three distinct competences characteristic of analytics, two of which ([a] and $[\mathbf{c}]$ ) are theoretical, while the other one is more practical:

[a] to know "how" or "from what" deductions are "produced" (or "what their inner structure is" - for the verb gignetai, which is used in both passages, does not necessarily mean a real process of production, but might refer only to the form of the so-called modes of syllogism);

[b] to be able to find appropriate deductions for any "problem" whatever (that is, every proposed conclusion);

[c] to understand how existing types of inference do conform to the "syllogistic" structures set forth in part [a], thus providing a posteriori corroboration for the results of that part. This part of the treatise, by far

\footnotetext{
${ }^{5} \operatorname{Pr}$ An. I, 43a 16-24.

${ }^{6} \operatorname{Pr}$. An. I, 46b $38-47$ a 9.
} 
the longest one, is based on the conviction that all our reasoning, or the largest part of it, can be explained through the models established in section [a]. Witness this declaration towards the end of Book II:

"Now, it should be explained that not only dialectical and demonstrative deductions come about through the figures previously mentioned, but also rhetorical ones, and absolutely any form of conviction whatever, arising from whatever discipline". (The text goes on: "For we have conviction about anything either through deduction or from induction", on which see below p. *9).

\section{Analytics and Topics}

The programme of the "practical" part [b] immediately reminds of the beginning of the Topics: "Our treatise proposes to find ways of proceeding (methodos) whereby we shall be able to reason deductively from reputable opinions about any subject presented to us, and also shall ourselves, when putting forward an argument, avoid saying anything contrary to it". ${ }^{8}$ The notions of "ways of proceeding" (methodos) $)^{9}$ and of "any proposed problem" indicate the same kind of prospect as in the Analytics. Even the definition of deduction is exactly the same in both treatises ${ }^{10}$ : "A deduction is a discourse in which, certain things being supposed, something different from the things supposed results of necessity because these things are so" - a fact which is generally recorded with some embarassment by the commentators, since the standard model of a syllogism is obviously absent from the Topics. But anyway, the aim of the Topics, seen as a whole and, so to say, "from outside", appears to be the same as that of the Analytics: to teach ways of finding premises for a given conclusion.

Nevertheless, there are also some significant differences between the two treatises. To begin with, the Topics passage makes two important qualifications : first, the aimed-at ability finds its place in a situation of contest or struggle, where one will have not only to find arguments, but also to defend oneself as well as to attack one's opponent; second, the Topics says that

\footnotetext{
${ }^{7} \operatorname{Pr}$. An. II 23, 68b 9-13.

${ }^{8}$ Topics I 1, 100a 18-21.

${ }^{9}$ The term methodos is echoed in the Analytics passage by that of a "way" (hodos). This same word recurs at the beginning of $\operatorname{Pr}$. An. I 30 to summarize the contents of chapters 27-29-on which see below, section 9.

${ }^{10} \operatorname{Pr}$. An. I 1, 24 b 18-20; Topics I 1, 100a 25-26.
} 
the relevant deductions should be based on "reputable opinions" 11 , while in the Prior Analytics no particular requirement is expressed as to the origin or status of the premises (In fact, the general notion of "premises for a given conclusion" seems to call for such specifications, according to the epistemic character of various types of conclusions and the contexts in which they are to be used. ${ }^{12}$ It is all the more noteworthy that the Prior Analytics seems to disregard that point.) Moreover, while the search for a method of finding deductions seems to be the sole aim of the Topics, it represents a comparatively small part of the Prior Analytics.

This raises the problem of the relationship existing between Topics and Analytics. The most ancient view on that subject commands the general plan of the Organon as we know it since Andronicus of Rhodes : after two short introductory treatises on simple terms (the Categories) and on propositions (De Interpretatione), comes a general, mainly or purely formal, theory of deduction (the Prior Analytics) followed by two special treatises : the Posterior Analytics on "demonstration" (apodeixis), i.e. scientific deduction, based on true premises, and another one about deduction from "reputable" premises, i.e. beliefs which are current among educated people or among specialists. One weakness of this model is that it breaks down the unity of the Analytics, which seems to me beyond reasonable doubt.

One might also consider the case from a historical point of view. It is generally admitted that the Topics was written at an early stage of Aristotle's career. But there are several cross-references between it and the Analytics, a fact that suggests not only that the treatise was still read by the time Aristotle was writing the Analytics, but also that the subject matter itself was probably still a part of the teaching programmes of the Lyceum.

We shall have to come back again to these issues in the last two sections of this paper ( $\$ 9$ and $\S 10)$. Although they may seem to be of merely historical interest, I believe that a more exact assessment of the relationships between Aristotle's different projects in the field of the theory of argumentation may greatly improve our understanding of their philosophical meaning.

\footnotetext{
${ }^{11}$ On this notion of "reputable opinions" (endoxa), see Topics I 1, 100b 21-23.

${ }^{12}$ The Rhetoric too is a handbook of argumentative discourse, and could be described (at least partly) by the same formula. Indeed, Aristotle stresses that his conception of rhetoric as an "art" (i.e. a technical study) owes much to his (presumably earlier) discoveries in the domain of dialectic and analytics. There is one important difference: rhetorical argumentation deals with objects that are actions and decisions, and therefore particular and contingent items. The distinctive inferential moves of rhetoric, enthymemes and examples, are closely corresponding to deductions and inductions, but the fact that they deal with particulars, makes them somewhat different from the standard analytical models of induction and deduction. On this see Crubellier 2007.
} 


\section{The analytic method}

Now, in what sense do the three parts that we have distinguished in the Prior Analytics implement one method, which may be aptly described as "analytic"? The verb analuein has here a strong and precise meaning: it indicates one definite act, by which the analyst divides the conclusion into two distinct propositions, which will be the premises, by chosing a convenient "middle term". The problema or "proposed conclusion" is a proposition, which - in the simplest cases - is made out of two terms. The middle term, freely introduced by the analyst, combines separately with each one of the two terms of the problema to give two new propositions. These propositions may - if the middle term has been aptly chosen - become the premises of a regular deduction or "syllogism". Thus, when Aristotle writes in the Metaphysics that "the parts are causes of the whole, and the hypotheses are causes of the conclusion, in the sense that they are that out of which these respectively are made", ${ }^{13}$ we have to take it literally. It appears (from some characteristic phrases that occur frequently in the Analytics and throughout the Corpus) that Aristotle often illustrated his "logical" explanations with diagrams in which a proposition of the form "A belongs to B" was figured by a vertical line, the predicate being at the top of it and the subject at the bottom (fig. l):

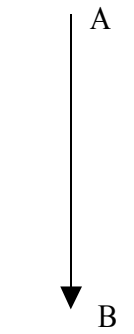

fig. 1

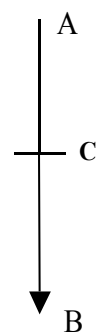

fig. 2

Then the essential analytical act is the setting of point $\mathrm{C}$ (fig. 2), the middle term, producing two new propositions, "A belongs to $\mathrm{C}$ " and " $\mathrm{C}$ belongs to B". Of course, further important points must be taken into account, which are well known by every person who has at least a basic knowledge of "syllogistic":

- The middle term need not necessarily be placed between A and B, as it is in our example (corresponding to the Aristotelian "first figure"); it may also be said to belong to B and to A as well (and thus be placed

\footnotetext{
${ }^{13}$ Metaphysics $\Delta 2,1013$ b 20-21
} 
"above" A, as is the case with the "second figure"), or to be a subject to which both A and B belong, and then be placed "under" B ("third figure"). ${ }^{14}$

- The relation between two given terms may be specified as affirmative or negative, universal or particular, and modalized in different ways.

- Not every combination of three terms (the so-called "moods") gives a valid deduction (i.e. conform to the above-mentioned definitions of deduction, i.e. such as the affirmation of the conclusion follows necessarily from the assumption of the premises). The role of part [a] of the Prior Analytics is precisely to determine which of them are valid and which are not. This is done in chapters 4 to 6 for non-modalized propositions, and in chapters 8-22 for modalized ones. It is worth noticing that this section is not "analytical" in the sense just defined, since it does not proceed backwards, from the proposed conclusion to the premises. But neither is it a constructive process, starting from simpler or more self-evident axioms or rules to infer from them more complex or less evident results. In fact, Aristotle generates all possible deduction models through a strictly combinatory process, then he checks each of them separately. He then rejects those that are not valid, giving an invalidity proof for each one, and gives proofs for the existence of a deduction for all the other cases. Even when he shows, in chapter 7, that all valid moods of the second and third figures can be reduced (analuesthai) to valid moods of the first, these are not meant to play the role of "axioms", the truth of which would ensure the validity of the second- and third-figure moods, but the aim of this (analytical) operation is just to corroborate the results that have been first obtained through the "combination plus elimination" procedure. The method is basically the same, although its application is often more complicated, in the exposition of modal deductions.

Thus, if the interpretation that I am advocating here is correct, it implies surprising as it might seem to some people - that these first chapters are not the core of Aristotle's project, but rather a preliminary step to the use of the analytical method in order to find [b] convenient starting-points for argumentation and to understand [c] our current modes of inference.

Another striking aspect of Aristotle's way of putting these matters is his insistence on figures, while modern accounts of "syllogistic" tend to give

\footnotetext{
${ }^{14}$ That may provide a sufficient explanation for the fact that Aristotle did not consider a «fourth figure».
} 
more importance to the moods. See for instance this judgment by Lukasiewicz: "The distribution of syllogisms into figures seems to have no other than a practical purpose: the point is to make sure than no true syllogistic mood is left out". ${ }^{15}$ On the contrary, Aristotle has no technical word for the "moods", while he refers constantly to the three figures in his analyses and explanations of kinds of inferences or errors, and so does he in the Posterior Analytics as well. This aspect of analytic method certainly deserves more attention from the scholars than it has received till now. Commentators have spent much ingenuity on the - purely formal - question of the so-called "fourth figure". But what strikes me most is the fact that figures are a really effective tool for the classification and assessment of various kinds of inferences, and for the tactical construction of some proofs. Aristotle seems to think that the differences between the figures do reflect significant differences in reality. ${ }^{16}$

\section{The third part of the Prior Analytics}

Besides the act of fixing the convenient middle term, or resting on this act, there are three main operations to which Aristotle refers by the verb analuein, all of which are brought into play in the third and longest part of the Prior Analytics:

1. To bring back a complex argument to a chain of elementary deductions matching the models set forth in part [a]:

This is only an extension through iteration of the basic analytical move. One can find an interesting illustration of such a process in chapters 1923 of Book I of the Posterior Analytics. The aim of this long and complicated argument is to show that there are complete scientific demonstrations ${ }^{17}$; even more, that every conclusion which is susceptible of demonstration can be brought back to a finite number of premises, i.e. that one can insert a certain number of middle terms (let us say $\mathrm{C}_{1}, \mathrm{C}_{2}$, $\mathrm{C}_{3}, \ldots$ ) between the terms of that conclusion, but that the process cannot go on indefinitely : the demonstration can be brought to a stage at which God himself could not find anything more to demonstrate in it.

\footnotetext{
${ }^{15}$ Łukasiewicz 1957, § 9.

16 "- What do you mean by "reality"? Our real processes of thinking, or relations between the things themselves, or between concepts thought of as objective realities? - Well, given Aristotle's epistemological realism, it might well be the three of them together."

${ }^{17}$ See below section 6 .
} 
2. To translate a piece of argument expressed in natural language, into syllogistic formulas:

The following lines offer an example of a situation in which the analyst might hesitate on how to translate conveniently:

"Something extra duplicated in the premises should be put with the first extreme, not with the middle. I mean, for instance, if there should be a deduction that there is knowledge in that it is a good of justice, then the expression 'in that it is good' (or 'qua good') should be put with to the first extreme. For let A be 'knowledge in that it is a good', B stand for 'good', C stand for 'justice'. Then it is true to predicate A of B: for of the good there is knowledge in that it is good. But it is also true to predicate $\mathrm{B}$ of $\mathrm{C}$ : for justice is essentially a good. In this way, then, an analusis comes about. However, if the expression 'in that it is a good' is put with B, then no analusis will be possible. For A will be true of $\mathrm{B}$, but $\mathrm{B}$ will not be true of $\mathrm{C}$ : for to predicate the term 'good in that it is a good' is incorrect and not intelligible". ${ }^{18}$ In order to extract the elementary terms of a deduction from the more complex structure of natural discourse, the difficulty is to individuate them correctly. The point at issue is the allocation of the phrase 'qua good' (or: 'that it is good'. The correct analusis produces a regular first-figure syllogism, with the predicate $\mathrm{A}=$ 'knowledge of $x$ qua good'. In the mistaken analusis, A becomes A' = 'knowledge', and B becomes B' = 'the good qua good'. Then it is indisputably true that there is a knowledge of the good qua good, but the minor premise: 'justice is a good qua good' is "false", in fact because the phrase 'good qua good' does not make any sense. ${ }^{19}$

3. To explain or show the effectiveness of various kinds of inference, even of those which are clearly distinct from deduction, for instance proofs by reduction to impossibility, or inductive inferences:

As to the reduction to impossibility, Aristotle says ${ }^{20}$ that, taken as a whole, it cannot be "analyzed" in the sense explained here. But one can distinguish two parts in it: (1) the general frame of the proof, i.e. the claim that if a given proposition $p$ is shown to lead necessarily to

\footnotetext{
${ }^{18} \operatorname{Pr}$ An. I 38, 49a 11-22

${ }^{19}$ Let me draw the attention of readers of the Metaphysics on the fact that this remark may concern the famous opening sentence of Book $\Gamma$ : "There is a science which considers being qua being", so that one is not allowed to extract from it the phrase "being qua being", as if it were the designation of something.

${ }^{20} \mathrm{Pr}$. An. I 44, 50a 29-38.
} 
an impossibility, then $p$ is false and not- $p$ is true; (2) the derivation of this impossible consequence. The latter can and must be given the form of a regular deduction, and thus it is analysable, while the effect of the former (i.e. that the opponent's claim proves untenable) rests on a dialectical rule: the impossibility to assume contradictory propositions. More generally, inferences that rest on a "hypothesis" with the effect of eliminating the possibility to admit certain claims are not analysable.

The case of inductive inference (Prior An. II 23) is perhaps the most interesting, to show the scope and distinctive efficiency of the "analytic" procedure. Aristotle describes it thus: "Induction, then, or rather a deduction from induction $^{21}$, is deducing one extreme to belong to the middle through the other extreme, for example, if $\mathrm{B}$ is the middle for $\mathrm{A}$ and $\mathrm{C}$, proving $\mathrm{A}$ to belong to $\mathrm{B}$ by means of $\mathrm{C}$ (for this is thow we produce inductions. For example, let $\mathrm{A}$ be long-lived, B stand for not having bile, and $\mathrm{C}$ stand for a particular long-lived animal, as man, horse, mule. Now, A belongs to the whole $\mathrm{C}$ (for whatever is bileless is long-lived ${ }^{22}$ ); but $\mathrm{B}$ (not having bile) belongs to every $\mathrm{C}$. If, then, $\mathrm{C}$ converts with $\mathrm{B}$ and the middle does not reach beyond the extreme, then it is necessary for $\mathrm{A}$ to belong to $\mathrm{B}(. .$.$) . But one must understand \mathrm{C}$ as composed of all the particulars; for induction is through them all" ${ }^{\prime 23}$.

Two features are particularly striking in this description:

(1) Here, contrary to the original presentation of analusis, the subject of the conclusion is called "the middle term". This departure from Aristotle's own constant usage may seem surprising. Why didn't he use rather the model of third-figure deductions, in which the middle term is set "outside" the [A, B] interval and below B? The reason for this is easily found: third-figure moods give only particular conclusions, while in the case of induction what is supposed to be inferred must be a universal proposition. (Another justification lies in Aristotle's express claim that this kind of inference is appropriate to a "primary and unmiddled premise ; for the deduction of those premises of which there is a middle term is by means of the middle term; but the deduction of those of which there is not a middle term is by means of induction". ${ }^{24}$

\footnotetext{
${ }^{21}$ More on this apparently strange phrase in the next section.

22 This parenthesis, which has shocked many scholars, must be read as a sort of commentary from an "external" point of view, so to say, and not as a proper part of the inference itself (since that would make it circular).

${ }^{23}$ II 23, 68b 15-29

${ }^{24}$ II 23,68 b 30-32
} 
But with this last remark he leads us beyond a mere theory of inference in general, since the notion of "primary and immediate propositions" is crucial to his theory of science, and maybe does not mean anything outside that context - on which see the next section).

(2) This apparent oddity is made good by the fact that the proposition: " $\mathrm{B}$ belongs to C" (e.g. "man, horse, mule are bileless") is assumed to be convertible. Thus, we obtain the following regular first-figure deduction:

(The) bileless animals are \{man, horse, mule\}

\{Man, horse, mule\} are long-lived

Bileless animals are long-lived

Here we may recognize the standard model Barbara, except that the middle term is the list $\{$ man, horse, mule\}. Thus, one could describe inductive inference as a kind of "deduction" in which the role of the middle term is played not by a single term, but by a list. This characteristic implies two weaknesses, which give rise to the "induction problem": (a) the unity of this middle term, and (b) its completeness, are not guaranteed. This is not the place to discuss these issues. But it is important to have in mind, while reading this chapter, that Aristotle is not claiming to introduce another type of deduction matching the standards of necessity and accuracy of the so-called "syllogistic". He is just trying to account for the fact that we do make such inferences as that of the bileless animals, and for the (limited and risky, but real) efficiency of that spontaneous activity of human mind. (Besides, he also says ${ }^{25}$ that it is more particularly appropriate to rhetoric than to science or technical reasoning - but we need not take him at his word, since, as we shall see, induction plays an important role in his theory of science). Seen that way, it is no misfortune, but rather a good point for Aristotle's analusis, if it raises interesting questions about this kind of inference.

In the same spirit, in one section of Book II of the Prior Analytics ${ }^{26}$ he "analyzed" various kinds of faults in reasoning by means of the three figures of deduction, with the intention to make his reader more able to avoid such

\footnotetext{
${ }^{25}$ Compare Pr. An. II 23, 68b 9-13, quoted above.

${ }^{26}$ II, $16-21$
} 
faults, or to detect them in his opponent's discourse. In other places, he even went further in that direction, since he made use of the "middle term" in order to explain and discuss some mental processes which have little or nothing to do with inference, such as the structure of definition ${ }^{27}$, the doubtful guesses of physiognomony ${ }^{28}$, the formation of voluntary decisions ${ }^{29}$, and even the practical tricks of mnemonics ${ }^{30}$. Clearly, he considered his discovery of the middle term to be a great achievement (and a great achievement it was, as we shall see). But fond of it as he may have been, his fondness did not lead him to uncritical enthusiasm, as we can see from the fact that he honestly admits that such - indisputably conclusive - modes of inference as proof by reduction to impossibility cannot be analyzed in that manner.

\section{Analytic method and the foundations of science}

I hope that what I have said so far may account in a satisfactory way for the contents and order of the Prior Analytics (please refer to the general plan given in the Appendix). But what about the Posterior Analytics? The textual data about the aim and plan of this treatise are not so clear as those that we have found in the Prior Analytics. The most obvious fact is the division into two main parts corresponding to the two books, the first one on demonstration and the second on definition - although its last six chapters (at least) are dealing with rather different topics, namely the method for setting problems (1415), causal explanations (16-18) and the knowledge of general terms (19). Each of the two books has a finely worked-out introduction, which sets out its subject in a methodical and philosophically illuminating manner, but both seem to end rather confusely, in a loose series of notes more or less closely related to their main topic (a feature which is not uncommon in Aristotle's treatises). Even the inner order of each book is far from being clear. The most clearly programmatic text in the Posterior Analytics is the beginning of Book II, which classifies the objects of knowledge under four headings: "the fact, the reason why, if it is, what it is" - which are straight after reduced to two, since Aristotle tells that knowing the fact is just a preliminary step to the knowledge of the "why", and knowing "that it is" is a step towards the knowledge of "what it is". Thus, we are left with two paths of scientific knowledge, the first one dealing with propositions, and the second one with simple terms.

\footnotetext{
${ }^{27}$ Post. An. II, 3-10; on which see section 8.

${ }^{28}$ Pr. An. II, 27.

${ }^{29}$ On the Soul III, 10-11; Movement of Animals, chap. 7; Nicomachean Ethics VI, 1142a 22-23; VII, 1147a.

${ }^{30}$ On Memory and Recollection, chap. 2.
} 
This in turn seems to correspond well enough to the subject matter of the two books, demonstrations on the one hand and definitions on the other. It suggests the picture of an independent treatise on science and its methods, with no or little connection with the problems of formal logic which form the whole substance of the Prior Analytics, despite the two passages that I mentioned at the beginning of this paper ${ }^{31}$, which seemed to presuppose a strong unity between the two treatises. In this case the title Analytics would have been given to the Posterior owing to the fact that demonstration is a kind of deduction, and nothing more (as in the commentators' vulgate).

Yet one can find in the PosteriorAnalytics clear indications that the problematic of finding a middle term is quite relevant to Aristotle's presentation of science. (1) At the beginning of Book II, immediately after having set out his typology of the objects of scientific inquiry, he adds: "in all our searches we seek either if there is a middle term or what the middle term is" ${ }^{\prime 32}$. This implies (2) that definition is susceptible of a kind of analysis: "we have said (...) how the "what it is' is explained into the terms" 33 and that in some sense definition might be considered as a demonstration of a kind, or at least is closely related to a possible demonstration: "and $<$ we have said $>$ in what way there is or is not demonstration or definition of it [= the "what it is']"34. Besides, I have already mentioned (3) the long demonstration of Book I, chap. 19-23, to the effect that a scientific demonstration can be brought to a state in which it is complete, i.e. that there is a finite number of middle terms between its predicate and its subject.

There are still other places in which there are limited, but often quite explicit resorts to analytic method ${ }^{35}$. But in order to complete that discussion, we should now concentrate on the first chapters of Book I, in which the relevance of analytics is not so immediately obvious. These chapters set out a comprehensive characterization of scientific knowledge, which seems to be drawn up on the basis of the notions that educated people of Aristotle's time, informed of the new advances of sciences (especially of geometry) and of the philosophical developments ${ }^{36}$ on the subject, had of a science. The start-

\footnotetext{
${ }^{31} \operatorname{Pr}$. An. I 4, 25b 26-31; Post. An. II 19, 99 b 15-16.

${ }^{32}$ II 2,90 a 5-6.

${ }^{33}$ II $13,96 a 20$.

${ }^{34}$ II 13,96 a 21.

${ }^{35}$ E.g. I 14 , I 15-16, or II 16-18.

${ }^{36}$ Mainly Plato, whose conceptions and vocabulary are clearly perceptible in these chapters. Compare Phaedo 99-100, or Republic, Books VI and VII.
} 
ing-point of this account is the following description of scientific knowledge : "We think we have scientific knowledge of something (...) whenever we are aware both of the explanation because of which the object is (i.e., that this is the explanation of that object), and that it is not possible for it to be otherwise" 37 - which in turn is spelled out in the following way : "If, then, scientific knowledge is as we posited, it is necessary for demonstrative knowledge in particular to depend on things which are true and primitive and immediate and more familiar than and prior to and explanatory of the conclusion". ${ }^{38} \mathrm{I}$ have kept Barnes' "things" to translate the neutral plural adjectives of the Greek original ; but the reference to the "conclusion" makes it clear that these "things" are premises. The special character of its premises distinguishes scientific knowledge, and thus it turns out that in a significant way the Posterior Analytics fit into the programme inaugurated by the Prior. One could even be tempted to go farther and consider them to be nothing but a part (although expanded at great length) of the original plan, in keeping with 99b15-17. There is indeed some continuity between the end of the Prior Analytics and the Posterior: after having dealt with the application of analusis to dialectical discussions (Pr. An. II, 16-21), next to rhetorical proofs (23-27), Aristotle would then come to apply it to scientific demonstrations and definitions. In other words, instead of opening in my Appendix a separate section 1.2, dedicated to Aristotle's theory of science, maybe I should rather have prefixed all the contents of the Posterior Analytics (with the exception of the last chapter) with 1. 136, parallel to my numbers 1.134 (dialectic) and 1. 135 (rhetoric).

But matters are slightly more complicated, since the overall view of scientific knowledge given at the beginning of Book I includes the statement of an important objection to the very possibility of such a knowledge, a "skeptical" objection already faced by Plato, ${ }^{39}$ which is best expressed in the form of a dilemma : either the scientific demonstration of any given proposition is an infinite task, or one will have to assume some premises without demonstration, which would amount to make scientific knowledge rest on arbitrary assumptions : "Now some think that because one must have scientific knowledge of the primitives, there is no science at all; others that there is, but that there are demonstrations of everything". Aristotle adds: "Neither of these

\footnotetext{
${ }^{37}$ I 2, 71b 9-12.

${ }^{38}$ I $2,71 \mathrm{~b} 19-22$.

${ }^{39}$ The adjective "skeptical" is most certainly anachronistic, since Pyrrho was much younger than Aristotle; but the above-mentioned dilemma became a standard of the skeptics' arsenal. Its occurrence in the Meno suggests a Sophistic origin.
} 
views is true, nor is it necessary that one of them should be the case". ${ }^{40}$ The whole theory of science expounded in the Posterior Analytics develops under the pressure of this objection, with the result that it has to deal not only with premises tout court, but with principles (archai), i.e. absolutely first premises (and first terms). Since the scientific character of demonstration depends on the truth, explanatory value and epistemic status of its premises, a theory of demonstration cannot consider a single deduction separately; in fact, it has to introduce a more architectonic point of view, in order to provide an account of the ultimate foundations of science. Aristotle has to dismiss the "skeptical" objection, which he does partly in Book I, as we have seen, by showing that there are complete demonstrations, and partly in the last chapter of Book II which is explicitly dedicated to that question and relates the formation of universal notions through perception, memory and language. The latter should itself be completed by Prior Analytics II 23, with its mention of "primary and immediate propositions". Although Aristotle speaks of "induction" in both contexts, there is a crucial difference between them: in $P r$. An. what emerges from induction is a conclusion, i.e. a proposition (that is why he allows himself the phrase "inductive deduction"), while in Post. An. it is a simple term.

Other consequences of this concern with the foundations of science are (1) the presence in the Posterior Analytics of some reflections upon the systematic order of sciences ${ }^{41}$ and the possibility of a unified science ${ }^{42}$, and (2) a celebrated classification (in chapter I 10) of the various types of "first principles", which is strongly reminiscent of Euclid's Elements ${ }^{43}$.

Because of these distinctive features, the Posterior Analytics cannot be called a mere part of the Prior Analytics project. The last chapter on the origin of universal notions will show how intricate the situation is: while this chapter lies clearly outside the scope of the analytical programme, since the psychical processes that it describes do not involve anything like a middle term, it is undoubtedly an essential part of Aristotle's answer to the skeptical

\footnotetext{
${ }^{40}$ I 3, 72b 5-7. In another place, Aristotle alludes to the Meno paradox: "you will learn either nothing or what you know" (I 1, 71a 30, compare Meno 80d).

${ }^{41}$ See for instance I 11, 77a 26-35, I 27-28, II 15.

${ }^{42}$ A perspective that Aristotle rejects; see Post. An. I 32.

${ }^{43}$ Euclid's books were probably written some decades after Aristotle's. But since he seems to have summed up the results of a tradition of geometrical treatises called Elements, it is hard to decide if there has been an influence in one or the other direction, or even a reciprocal influence. Euclid himself does not comment on his method, neither does he express epistemological views of his own; the oldest commentary that we have on the Elements is the work of Proclus who, as any good Neoplatonist, had had a thorough training in the Organon. At any rate, the Posterior Analytics and the Elements, like two symmetrical monumental pillars, were to form the portico of the temple of scientific method for generations of Western philosophers.
} 
objection, and thus of the Posterior Analytics. So, I am inclined to think that these were written independently of the Prior Analytics, most probably after them and perhaps many years after, but that Aristotle was conscious that he was deepening and increasing the kind of research he had initiated in his former treatise. That may be the reason why he referred to both of them by the same general title.

\section{An overview of the Posterior Analytics}

We are now in a position to get a clearer picture of the contents of the Posterior Analytics.

In the first 14 chapters of Book I, as we have seen, Aristotle characterizes scientific demonstration by means of a series of constraints bearing on the premises. I leave it to the reader to see how these constraints are related to the general description of scientific knowledge, and to follow their systematic exposition in chapters 2 to 15 , since this first section is comparatively well ordered, and has been thoroughly examined by Aristotelian scholars. ${ }^{44}$ Notice that it ends in chapter 14 with the typically analytic remark that the first figure is more fit for scientific knowledge than the other ones.

Next come three chapters (16-18) on "ignorance" (agnoia), which is certainly introduced here as a counterpart of knowledge. The interesting fact is that it is defined as "error coming about through deduction", ${ }^{45}$ and analyzed in order to locate precisely the original source of the mistake, following the schemes of the three figures.

In my plan, I have treated chapters 19 to 26 as one section, under the general heading of "the ideal demonstration" (1.213). Maybe it would have been more accurate to distinguish and separate its two constituents, since the first part (19-23) upholds a particularly strong thesis (the existence of finite complete demonstrations) which is crucial to the possibility of science, while the following chapters (24-26) intend only to compare the demonstrative values of different kinds of inferences.

The rest of Book I may be considered as a rather discontinuous stretch of additional notes, related in various ways to the main contents of the book: some of them concern the kinds of facts which are object of scientific knowl-

\footnotetext{
${ }^{44}$ Non-Aristotelian and Greekless readers will find Jonathan Barnes' commentary (Barnes 1994) particularly helpful.

${ }^{45}$ Post. An. I 16, 79b 24.
} 
edge (chapters 30-31, 33), others discuss larger issues about the systematic order of sciences $(27-28,32)$, and the last chapter is about "exactness of mind" or "acumen".

The main part of Book II is about definitions. As we have seen, this large division of Posterior Analytics in two parts is explicitly based on a systematic classification of the objects of scientific inquiry. ${ }^{46}$ There is no problem about that, but it is worth noticing that in Aristotle's view, a definition is a piece of knowledge and may be true or false. Which is more, a real definition is not an immediate piece of knowledge : if you define thunder as "a noise in the clouds" or an eclipse as "privation of light from the moon", you will have captured only the fact "that it is" ; to express what it is in a precise and intelligible way, you have to tell that thunder is a noise caused by the quenching of fire in the clouds ${ }^{47}$, and eclipse a privation of light from the moon by the earth's screening. ${ }^{48}$ Thus a scientific definition can be analyzed. Nevertheless, it has not the same status as a demonstrable proposition. Here Aristotle's discussion may fairly seem somewhat embarrassed : sections 3-7 and 8-10 are near to contradict each other, and the final result is that definitions (at least some of them, and the most interesting ones) are demonstrations of a kind, "oblique" demonstrations, so to say, "differing in aspect from demonstration" ${ }^{49}$ Maybe one should say that such a definition "contains" a demonstration, either because it recapitulates a demonstration or because a demonstration is potentially present in it.

Another problem with this section on definitions is to mark exactly where it ends. Since chapter 13 gives directions on how to find definitions, it may seem that the section extends as far as that (and this is the division I adopted in the Appendix). But chapters 11 and 12 deal with the middle term as an expression of the cause, and this discussion is not necessarily limited to the middle terms of definitions (especially in the case of chapter 12, which raises an issue about the retrodictive $v s$. predictive character of causal explanations). So, it might be more appropriate to consider chapters 11 to 18 of Book II as a larger heuristic section, parallel in a way to the heuristic section of Prior

\footnotetext{
${ }^{46}$ Barnes 1994 explains the general division of the Posterior Analytics by saying that Book I put forward the necessity to base scientific knowledge on first principles, and that definitions are among these first principles (p. xiii). This is true, but why put the stress on definitions rather than on some other kind of principles? One explanation might be that of all the principles, definitions are not as "first" as the other ones, since they feature a middle term.

${ }^{47}$ Post. An. II 10, 94a 5.

${ }^{48}$ Post. An. II 2, 90a 15-16.

${ }^{49}$ Post. An. II 10, 9412-13.
} 
Analytics (1. 12 in my plan) and bearing on all the matters examined in the Posterior, i.e. precepts for (1) finding causes (chapters 10-11), (b) searching definitions (13) and (c) setting a problem clearly (14-18). ${ }^{50}$

\section{Why so few formal syllogisms in the Aristotelian treatises?}

Incidentally, grasping the distinct purpose of analytic method may cast a new light on a notorious puzzle about the Posterior Analytics and help, if not to solve it, at least to show there is not so much harm in it as is commonly believed. It has been noticed long ago that, while Aristotle expressly claims that scientific knowledge must take the form of demonstrations, which are themselves a kind of syllogisms, there are astonishingly few recognizable syllogisms in the rest of the Corpus. While some ancient and medieval commentators painstakingly tried to rephrase Aristotle's bright, creative and intuitive analyses into regular formal syllogisms, some of the moderns tried other ways out. Weil ${ }^{51}$ suggested that the treatises pertained to the province of dialectic - but that would seem to pass over what Aristotle explicitly says of the epistemological hierarchy of science and dialectic, and over the many places in the corpus where he calls his reader's attention on the fact that he will proceed dialectically (logikôs) as opposed to phusikôs, which must mean : "according to the standards of natural science". ${ }^{52}$ Barnes added ${ }^{53}$ the suggestion that the description of complete and logically faultless demonstrations based on true premises was meant to hold only as the ideal picture of an achieved science. But it seems that we are not much better off with that, since Aristotle himself glosses the phrase "scientific deduction" with these words: "by 'scientific' I mean one in conformity with which, by having it, we have scientific knowledge of something". ${ }^{54}$ There are some facts of which there is a demonstration, and this is an objective property that they have: i.e., their notion can, and indeed must, be analyzed into more fundamental terms, which manifest their cause. Thus, to have a scientific knowledge of them is to know them under the form and in the order that the demonstration exhibits. Aristot-

\footnotetext{
${ }^{50}$ A third alternative, of course, would be to admit that here too we have just a disordered series of endnotes.

${ }^{51}$ Weil 1951.

52 There is even one place where logikôs is opposed to analutikôs (although analytics is not properly a science): Post. An. I 22, 84a 7-8.

${ }^{53}$ Barnes 1994, p.xii-xiii (these pages date from the first edition, 1975. Barnes qualified his poosition in an addition in the second edition, pp. xviii-xix).

${ }^{54}$ Post. An. I 2, 71b 18-19 (italics mine).
} 
le specifies, "by having it" to exclude the case in which someone would come by chance to think of those things in that order, but without being aware that this is a demonstration. If this is so, to say that we are not yet in possession of such demonstrations means that we have, at least for the time being, no science at all. Aristotle would not have shared such pessimism or modesty.

Now, once it is clear that the distinct epistemological contribution of the Analytics does not consist in prescriptive rules concerning the logical form of scientific discourse, but rather in an explanation of the specific nature of scientific knowledge, there is no reason to consider that an argument is unscientific because it has not the canonical form of a syllogism. It is scientific as soon as it is conclusive, rests on necessary true premises and has some explanatory value. It may be interesting and useful (in order to show that it is conclusive, among other things) to translate it later on into a canonical deduction, but this is not necessary, neither does it add anything to its scientific value.

I would like to illustrate my point in reference to a case which is commonly considered to be particularly disadvantageous to Aristotle, namely mathematical reasoning. He is often blamed for having given a distorted picture of mathematics by claiming that geometrical proofs were demonstrations in his sense of the word, i.e. syllogisms. In fact, he even goes so far as to claim that the proofs of "arithmetic, geometry and optics" are first-figure syllogisms. ${ }^{55}$ Contrast for instance Kant's clear-cut distinction between "philosophical" (i.e. syllogistic) deductions and geometrical reasoning "through construction of concepts" ${ }^{56}$ The interpretation that I have sketched here could help to face this difficulty. For he may have meant that geometrical proofs are demonstrations because they bridge the interval between a given object (e.g. the triangle) and a given property (e.g. to "have two right angles") by means of a middle term: the three angles "disposed around one point" so as to make appear that they are equal to two right angles. ${ }^{57}$ This is in keeping with what he writes about analusis as a standard procedure for the resolution of geometrical problems. For all that, I do not wish to claim that Aristotle had a clear understanding of the nature of geometrical proofs and their often complex structure, nor that his analytics, with its linear topology, could have given the

\footnotetext{
${ }^{55}$ See Post. An. I 14 - a claim which he justifies by saying that the first figure is the only one that can provide universal affirmative conclusions.

${ }^{56}$ Critique of Pure Reason, "Transcendental Methodology”, part I, section 1.

${ }^{57}$ Metaphysics $\Theta 9$, 1051a 24-25.
} 
means of an adequate description of mathematical reasoning. But in any case, he must not be charged with blind dogmatism with regard to these questions; at the most, he may seem to be guilty of some vagueness or carelessness.

\section{Is there an ars inveniendi in the Analytics?}

Alongside this role of accounting (a posteriori) for our effective processes of inference, the Analytics claim to pursue another methodological goal, which is to make the reader, or the practising student, able to find premises by himself so that he "will never fall short" (euporêsei) of deductive arguments. This part of the analytic programme is unquestionably prescriptive; but does that mean that there is a systematic method, i.e. a set of rules establishing a specific way of proceeding and possibly ensuring, under optimal or even under normal conditions, a successful outcome?

Something like that ${ }^{58}$ appears in the central section of the Prior Analytics (I, chapters 27-31, labelled [b] above). At the juncture of chapters 29 and 30, for instance, Aristotle writes: "It is evident from what has been said, then, not only that it is possible for all deductions to come about through this route (hodos), but also that this is impossible through any other (...). The route is the same with respect to all things, then, whether concerning philosophy or concerning any kind of art or study whatever". ${ }^{59}$ Notice Aristotle's insisting on the fact that this method is the same for all kinds of disciplines, that is, probably, that it is independent of the distinction between science and dialectic, and thus of any restrictive condition concerning the epistemic status of the premises.

The general scheme is as follows. ${ }^{60}$ Let the proposed conclusion be of the type "A applies to E". Then you have to make six different lists of terms:

three lists of terms related to $\mathrm{A}$ (the predicate):

(B) terms which follow from $\mathrm{A}$

(Г) terms of which A follows

$(\Delta)$ terms which are incompatible with $\mathrm{A}$

\footnotetext{
${ }^{58}$ There is also a very similar passage about the search for definitions in Posterior Analytics II, chapter 13.

${ }^{59}$ Prior Analytics I 29-30, 45b 36 - 46a 2.

${ }^{60}$ In the following lines, I am freely paraphrasing chapter 28 from 44a 11 on. I kept Aristotle's Greek letters to name the different terms and lists (except $\mathrm{M}$, the middle term, which is my own addition), but I limited myself to one example, while Aristotle, of course, examines at length all possible cases.
} 
three lists of terms related to $\mathrm{E}$ (the subject):

(Z) terms which follow from $\mathrm{E}$

(H) terms of which E follows

$(\Theta)$ terms which are incompatible with $\mathrm{E}$.

Now, a term which is common to one of the predicate-related lists and one of the subject-related lists may (with certain restrictions that I will not consider here) be used as a middle term in order to demonstrate that $A$ applies (or: does not apply) to (every, or a certain) $E$. For instance, if you have to demonstrate that vine is deciduous, you have to find a term such as broad-leaved, which is implied by the notion of vine (so that broad-leaved is a member of the list $\mathrm{Z}$ ) and implies the character deciduous (and thus is also a member of the list $\Gamma$ ). In chapter 28, 44a 17-19, Aristotle establishes that if a term M belongs to both $\Gamma$ and $\mathrm{Z}$, then it follows that A applies to every E, and that this can be demonstrated by means of $\mathrm{M}$ in the first figure, according to the standard Barbara formula:

A applies to every $\mathrm{M}$

$\mathrm{M}$ applies to every E

A applies to every E.

A similar determination of the middle term may be given for every other valid syllogistical mode.

To what extent can this be called a method for finding demonstrations? Aristotle's own assessment is strikingly balanced, as we may see from the last lines of chapter 30:

"Consequently, if the facts concerning every subject have been grasped, from then on we are prepared to bring the demonstrations readily to light. For if nothing that truly belongs to the subject and to the predicate has been left out of our collection of facts, then concerning every fact, if a demonstration for it exists, we will be able to find that demonstration, and demonstrate it, while, if by its nature it does not admit of a demonstration, we will be able to make that evident." ${ }^{\prime 1}$

${ }^{61}$ Prior Analytics I 30, 46a 22-27. 
That may sound proud and self-confident. Indeed, Aristotle has brought out a very important result, namely, that (1) every (direct) demonstration must have the form of one of his syllogistic models, and that (2) the middle term always satisfies the condition of being at the intersection of two different lists, one of predicate-related terms, and the other of subject-related terms. Yet, in order to establish this theorem, he had to suppose that we dispose of six complete lists $\mathrm{B}, \Gamma, \Delta, \mathrm{Z}, \mathrm{H}$ and $\Theta$. The difficulty lies less in the fact that some of these lists may be very long ${ }^{62}$ than in the lack of any general or formal mark to ascertain that a given term belongs to a given list and, still the more, to ascertain that the list has been completed. That is probably the reason why, in the same chapter, Aristotle reminds his reader that all knowledge rests ultimately on experience:

"The majority of principles for each science are peculiar to it. Consequently, it is for our experiences concerning each subject to provide the principles. I mean, for instance, that it is for astronomical experience to provide the principles of the science of astronomy (for when the appearances had been sufficiently grasped, in this way astronomical demonstrations were discovered; and it is also similar concerning any other art or science whatsoever". ${ }^{63}$

Thus, in the space of a few lines, Aristotle utters two strong and seemingly conflicting theses: (1) he claims that there is a universal "method" to determine with certainty the appropriate premises for any given conclusion; (2) he maintains the essentiality of experience. Here we meet, in fact, with the main difficulty for every project of an ars inveniendi: it has to stipulate rules and procedures that must be at least partly independent from the material import of that conclusion. Otherwise the very idea of a special, "instrumental" method would be meaningless, and the only necessary and sufficient requirement for finding convenient premises would be a thorough and accurate knowledge of the subject matter. But on the other hand, one cannot discover anything without some substantial knowledge of the investigated objects, especially (in Aristotle's view) of their essence. It is interesting to notice that both the-

\footnotetext{
${ }^{62}$ This must be the case with $\Delta$ and $\Theta$, i.e. the predicates that cannot apply to either the subject or the predicate of the proposed conclusion. The other four lists (terms that necessarily imply, or are necessarily implied by, the subject or the predicate) should be relatively short, since in Aristotle's view the essence of any real being is finite and can be known very precisely. But even the «negative» lists $\Delta$ and $\Theta$ might well be finite, (though probably very long in most cases) since thay should contain only properties that are always incompatible with A (or E), which implies some necessary relation to A's (or E's) essence.
}

${ }^{63}$ Prior Analytics I 30, 46a 17-22. 
ses occur together in an apparently anti-Platonic context. ${ }^{64} \mathrm{He}$ attacks Plato, so to say, from two opposite sides: as regards formal analysis, he claims the superiority of his own method for finding the premises, saying that Plato's method of division is "only a small part" of it ; at the same time, he stresses that you cannot discover anything without experience, which implies that a purely formal method would be fruitless. In doing so, he was not necessarily inconsistent or unfair. He may have had in mind the idea that Plato's dialectic was unduly mingling formal features (i.e., based on logical relations between the terms) and elements of contents based on empirical knowledge. The interesting move he made in chapter 30 consists in distinguishing the formal from the empirical element, although he appears to have thought that both are always necessary in order to acquire any piece of real knowledge whatever.

Thus the "method" explained in chapters 27-29 of Prior Analytics I has its limts. It is not entirely devoid of heuristic efficiency, since it specifies which kind of relationship the middle term must have with one each of the terms of the conclusion. But it cannot go any futher, because every research must incorporate some amount of experience, i.e. some acquaintance with the things themselves, plus a special aptitude to discern the essence of each one from the collection of all its properties. To describe this particular combination, Aristotle often uses the metaphor of hunting. ${ }^{65}$ Although hunting is not a random activity (it has certain rules and can be pracised in a more or less rational way), it can never be made entirely independant of chance. Admittedly, the metaphor may refer to quite different situations. The method described in Prior Analytics I 27-30 looks more like beating over a large area in order to rouse the game; but this may take a long time, while there are also more direct ways of doing, such as follwing a track or standing on the watch in a place where one knows that the game is likely to show up. Not by chance does the first book of the Posterior Analytics end with a note on "exact mind", by which some people prove able to "hit upon the middle term in an imperceptible time". ${ }^{66}$

So, I have to refine (and perhaps to complicate a little) the overall picture of the Prior Analytics I gave in section 2 above. Section [b], although it seemed to be introduced as the practical part of the programme, has also a

\footnotetext{
${ }^{64}$ Smith 1989 , p. 157 . The anti-Platonic scope is confirmed by the next chapter (I 31), which criticizes the Platonic «method of division».

${ }^{65}$ See for instance : «...in what way one ought to hunt for $<$ the principles of deductions» (Pr. Anal. I 30, 46a 11-12), and in a very similar context, about definitions : «...how one ought to hunt for the predicates that are contained in the what-it-is». (Post. An. II 13, 96a 22-23).
}

${ }^{66}$ Post. An. I 34, 89b 10-11. 
theoretical aim, i.e. to sum up the results of part [a] by means of a new and shorter proof. Symmetrically, practical concerns often come near to the surface of part [c], since it contains a lot of instructions and dwells often on the strong or weak points of the various kinds of inference it examines, as well as on the mistakes to avoid and the causes of error.

\section{Back to the relationship between Analytics and Topics}

As we have seen, both treatises follow a backward path. Both aim at discovering models of inference with some degree of generality, but in two very different ways.

The Topics is mainly a long catalogue of "places" (topoi) $)^{67}$, a term which belongs to the special idiom of dialectic and rhetoric. A "place" is, in Brunschwig's illuminating phrase, "a premise-making device", ${ }^{68}$ which tells us how to construct, on the basis of the proposed conclusion, another proposition which entails it, so that once our opponent has granted this proposition, he cannot escape the conclusion. ${ }^{69}$ The making of such devices presupposes the identification of certain standard types of proposition, with some characteristic features, which allow stating, as a general rule, that a proposition of type $\mathrm{T}_{1}$ entails a proposition of type $\mathrm{T}_{2}$. This will appear more clearly through a few examples:

$$
\begin{aligned}
& \text { "That which is in itself the cause of good is more desirable than what } \\
& \text { is so per accidens, e.g. virtue than luck, for the former is in itself, and } \\
& \text { the latter per accidens, the cause of good things". }{ }^{0}
\end{aligned}
$$

\footnotetext{
${ }^{67}$ This literal translation is to be preferred to the less surprising "commonplace", since in some contexts (e.g. in the Rhetoric) Aristotle makes a distinction between "common" and "special" topoi. The metaphor seems to refer to the "places" where a tidy person is sure to find the objects that he has stored there (Lausberg 1974, § 373); Aristotle himself suggests a connection with mnemonics (Topics VIII 14, 163b 28-32).

${ }^{68}$ Brunschwig 1967, p. xxxix.

${ }^{69}$ This account must be oversimplified, because it is not possible to set out conveniently here the problems raised by this kind of argumentative structure. It is to be specified at least that a "place" is not always a positive argument as in the example given above; it may also be used in view of a refutation (in cases in which $T_{2}$ implies $T_{1}$, so that the negation of $T_{1}$ entails the negation of $T_{2}$ ). Other interesting but difficult questions are (1) how the rule determining the content and form of $\mathrm{T}_{1}$ on the basis of $\mathrm{T}_{2}$ can be discovered and validated, and (2) the motives and meaning of the general classification of "places" offered by Aristotle in the Topics, on the basis of the "four predicables", namely accident, genus, proper, and definition.

${ }^{70}$ Topics III 1, 116a 1-2.
} 
(2) "If one predicate is asserted of two subjects, then if it does not belong to the subject to which it is the more likely to belong, neither does it belong where it is less likely to belong; while if it does belong where it is less likely to belong, then it belongs as well where it is more likely". ${ }^{71}$

(3) "If justice is knowledge, then injustice is ignorance: and if 'justly' means 'knowingly' and 'skilfully', then 'unjustly' means 'ignorantly' and 'unskilfully'; whereas if the latter is not true, neither is the former, as in the instance given just now - for 'unjustly' is more likely to seem equivalent to 'skilfully' than to 'unskilfully". ${ }^{72}$

These are "places". Some of them are not unfamiliar to us: perhaps the reader recognized in (2) our mode of reasoning a fortiori, and in (3) one version of our a contrario. Each of these examples shows a particular argument, which is supposed to be an instance of a more general rule. But, as one can easily see in (3), this rule itself is not necessarily incontrovertible. It may be only "likely", and its relevance to the case in point may also be questioned. This is one important difference with the deductive moods of the Prior Analytics, which are necessarily "true". Thus, dialectical inferences are not only based on simply plausible premises, they also need not be conclusive.

But this is in fact the consequence of another, more fundamental difference: "topic" types of argument, general as they may be, still retain some elements of content, while the deductive moods of the Prior Analytics are purely formal (or, more precisely, they are syntactically formal. For, in a sense, it might be said that the universal "places" of the Topics are formal, as opposed to the more special arguments which are proper to some particular science; but the relevant form is "semantical" form). So the topic way of looking for premises must end in a limited kind of universality, while the analytical formulas are not only "more universal" than the places; in fact they are universal in an entirely different way. Between he Topics and the Prior Analytics Aristotle made a grand discovery: he discovered logical form.

I would like to go a little farther and try a plausible guess about how Aristotle, starting from the Topics, eventually came to his notion of formal models of deduction. ${ }^{73}$ Places such as those I have described above, are in fact anagogic arguments (or arguments "by reduction") which in principle in-

\footnotetext{
${ }^{71}$ Topics II 10, 115a 6-8.

${ }^{72}$ Topics II 9, 114b 8-13.

${ }^{73} \mathrm{I}$ am freely drawing this hypothesis from a suggestion made (though on the basis of quite different presuppositions and concerns) by Hintikka 1993.
} 
volve two distinct moves: (1) a "shift" from proposition $\mathrm{T}_{2}$ (the problema) to proposition $\mathrm{T}_{1}$, and (2) an argument to make $\mathrm{T}_{1}$ hold. The Topics concentrates on the first move, and seems to assume that the dialectician will somehow manage to have his opponent grant proposition $\mathrm{T}_{1}$. But Aristotle may have wondered how this could be done. The most immediate solution is that, in the course of a dialectical discussion, the opponent be asked: "Do you admit that $\mathrm{T}_{1}$, or not?" and give an affirmative answer. But one cannot be sure that this will work. So, Aristotle may have been led later on to contemplate the possibility of a special proof for $\mathrm{T}_{1}$, and then to find the device of the two premises with one common (middle) term.

A variant of this guess would be as follows. At a most abstract level, the general formula of a topos is: "if the proposition that you want to establish (or refute) has the form $\mathrm{C}$ (in which convenient variables are substituted for the terms referring to the special subject-matter), then it will be necessary and/or sufficient to establish another proposition of the form $\mathrm{P}$, where the same variables occur and may be replaced by the relevant material terms". Now this description, with one important but limited modification (i.e.: “... it will be sufficient to establish a pair of propositions $\mathrm{P}_{1}$ and $\mathrm{P}_{2} \ldots$..), could fit the syllogistic figures; so that the figures could have been discovered as topoi of a certain sort, particularly effective but requiring the determination of an appropriate middle term.

Be that as it may, the discovery of purely formal models must have marked a turn in Aristotle's philosophy of inference. From then on, the Topics was outclassed by the Prior Analytics; that is the reason why it was not properly integrated into the new analytical project. But neither was it altogether discarded, as we have seen. Why did Aristotle keep it alive? The most plausible answer is that he recognized its specific value as a means of finding new arguments. As we have seen, the "heuristic" parts of the Prior and PosteriorAnalytics are far from being as rich and fruitful as the Topics, because the Topics benefits from the resources of semantical analysis, while in the Analytics the "hunting" for premises or definitions draws mainly from past experience and memories of acquired knowledge ${ }^{74}$ or depend on the good luck of an "exact mind".

\footnotetext{
${ }^{74}$ See Pr. An.I 27 ; Post. An., I 34 and II 13.
} 


\section{References}

Barnes, J (1984). The Complete Works of Aristotle, 2 vols. Princeton: Princeton University Press.

Barnes, J. (1994). Aristotle's Posterior Analytics. Oxford: Clarendon.

Brunschwig, J. (1981). "L'objet et la structure des Seconds Analytiques d'après Aristote", in Berti, E. (ed.), Aristotle on Science. The Posterior Analytics. Padova: Antenore, pp. 61-96.

Brunschwig, J. (1967). Aristote, Topiques I-IV, éd. et trad. par J. Brunschwig. Paris: Les Belles Lettres.

Burnyeat, M. (1981). "Aristotle on Understanding Knowledge", in Berti, E. (ed), Aristotle on Science. The Posterior Analytics. Padova: Antenore, pp. 97-139.

Corcoran, J. (1974). “Aristotle's natural deduction system”, in Corcoran, J. (ed.), Ancient Logic and its Modern Interpretations. Dordrecht-Boston: Reidel, pp. 85-131.

Crubellier, M. (2008). "Aristotle on the ways and means of rhetoric", in Gabbay, D.M., Canivez, P., Rahman, S. \& Thiercelin, A., Approaches to Legal Rationality. Dordrecht: Springer.

Crubellier, M. \& Pellegrin, P. (2002). Aristote. Le philosophe et les savoirs. Paris: Seuil.

Hintikka, J. (1993). "Socratic Questioning, Logic and Rhetoric", Revue Internationale de philosophie 184: 5-30.

Lausberg, H. (1974). Handbuch der literarischen Rhetorik, 2 vols. München: Max Hueber.

Łukasiewicz, J. (1957). Aristotle's Syllogitic from the Standpoint of Modern Logic, $2^{\text {nd }}$ edition. Oxford: Oxford University Press.

Mueller, I. (1974). "Greek Mathematics and Greek Logic", in Corcoran, J. (ed.), Ancient Logic and its Modern Interpretations. Dordrecht-Boston: Reidel, pp. 35-70.

Smith, R. (1989). Aristotle: Prior Analytics. Translation and commentary by R. Smith. Indianapolis: Hackett Publishing Company.

Weil, E. (1951). "La place de la logique dans la pensée aristotélicienne", Revue de Métaphysique et de Morale 56 (1951), pp. 283-315; English 
translation: "The Place of Logic in Aristotle's Thought" in Barnes, J., Schofield, M. \& Sorabji, R.: Articles on Aristotle, vol. I, London (Duckworth) 1975, pp. 88-112.

\section{Appendix: A general plan of the Analytics}

1. On Deduction

1. 1 A general theory of deduction (Prior Analytics)

1. 11 Systematic exposition of the elements (or: "How deductions are constituted", Bk I, 1-26) :

1. 111 Basic propositions and their conversions (I, 2-3)

1. 112 Construction of elementary deductions, non-modal (I, 4-7) and modal (I, 8-22)

(classified according to the three figures)

1. 113 Explanation of the structure of elements (I, 23-25)

1. 114 Another classification of elementary deductions: "which problems are easy / difficult to solve" (I, 26)

1.12. Heuristic (or: "How to find appropriate deductions for any proposed conclusion", Bk I, 27-31):

1. 121 Precepts for the choice of premises (I, 27-30)

1. 122 Criticism of Plato's "method of division" (I, 31)

1. 13 Analysis of existing processes of inference (Bk I, 32-3, and Bk II):

1. 131 Some precepts for the translation of natural-language sentences into "syllogistic" formulas (mainly negative precepts, i.e. aimed at avoiding errors) (I, 32-43)

1. 132 Cases of deductive inference that cannot be (or cannot be entirely) analysed (I, 44-45)

(A remark about negative conclusions-on the difference between "not being $A$ " and "being not- $A$ ", I, 46)

(A remark about universal and particular syllogisms, II, 1) 
1. 133 Analysis of some remarkable cases of deduction (deduction of true from false, circular reasoning, reduction to impossibility) (II, 2-15)

1. 134 Analysis of some faults in arguing (in dialectical situations) (II, 16-21)

(Two remarks (II, 22):

- about cases in which these extremes are coextensive

- about axiological reasoning)

1. 135 Analysis of rhetorical models of inference (induction, example, apagôgê, objection, enthymeme) (II, 23-27)

1.2 Analysis of scientific deduction (or demonstration) (Posterior Analytics)

1. 21 Theory of science (Bk I)

1.211 Definition of science (I, 1-15)

1. 2111 Definition of science; statement of the "skeptical" objection “(I, 1-3)

1. 2112 Further development of the definition: specific constraints for the premises of scientific demonstrations (I, 4-13) :

1. 21121 They must be necessarily true and universal (I, 4-9)

1. 21122 They must be 'first' (undemonstrable) and 'proper' (I, 9-12)

1. 21123 They must indicate the cause (I, 13-14)

(Remark: there are immediate negative propositions, I, 15)

1. 212 Analysis of ignorance (I, 16-18)

1. 213 The ideal demonstration (I, 19-26):

1. 2131 Demonstration of the possibility of a complete demonstration (= solution of the skeptical objection) (I, 19-23)

1. 2132 Comparison between the different types of demonstration: universal demonstrations are better than particular ones, affirmative better than negative and direct better than indirect (I, 24-26) 
1. 214 Some consequences for the theory of science:

1. 2141 There are ordered series of sciences (I, 27-28)

1. 2142 There may be several demonstrations of the same proposition $(\mathrm{I}, 29)$

1. 2143 Chance events and sensible facts are not objects of science (I, 30-31)

1. 2144 It is impossible that all demonstrations could have the same principles (?) (I, 32)

Two further remarks:

- about science and opinion (I, 33)

- about "acumen" (I, 34)

1. 22 Theory of definition (II, 1-13):

1. 221 The four objects of knowledge: the fact and the 'why', existence and 'what it is' (II, 1-2)

1. 222 A definition cannot be reduced to a demonstration (II, 3-7) ...nevertheless it can be analysed as the setting of an appropriate middle term (II, 8-10)

1. 223 The middle term indicates a cause (II, 11-12)

1. 224 Precepts for searching definitions (II, 13)

1. 23 The analysis of scientific problems (II, 14-18)

1. 231 General remarks (II, 14-15)

1. 232 Difficulties about the explanatory role of the middle term (II, 16-18)

2. The discovery of the first principles of science, and how we know them (II, 19) 
